\section{PERSPECTIVAS TEÓRICAS E O TRABALHO COM A PRODUÇÃO DE TEXTO NA COLEÇÃO DE LIVROS DIDÁTICOS PRODUÇÃO DE TEXTO PARA O ENSINO MÉDIO}

Jaqueline Teodora Cardoso da Costa

Pontifícia Universidade Católica de Minas Gerais. Doutoranda em Língua Portuguesa e Linguística pelo Programa de Pós-graduação em Letras. omando como objeto de estudo a coleção de livros didáticos Produção de Texto para o Ensino Médio, este trabalho tem como objetivo analisar o tratamento dado à produção de texto, a fim de verificar se as atividades propostas são coerentes com os pressupostos teóricos apresentados como balizadores do trabalho desenvolvido nos livros didáticos. Para isso, elegeu-se um conjunto de categorias que, conforme se buscará mostrar, estão implicadas na base teórica eleita pelas autoras. Assim, verificar-se-á se o trabalho com a escrita, proposto nessas atividades, leva, realmente, em consideração o fato de que a linguagem é um sistema de caráter interacionista em que o enunciador se constitui na relação que estabelece com o enunciatário por meio da palavra.

Palavras-chave: Produção de texto. Gênero textual. Livro didático. Interação. 


\section{Gênero textual e o ensino/aprendizagem da escrita}

É notório que o ensino de língua portuguesa passou por inúmeras transformações nas últimas três décadas em função das investigações promovidas pela Linguística e suas subáreas, como a Linguística do Texto, Análise do Discurso, Sociolinguística e Pragmática. Muitas delas trouxeram importantes contribuições, principalmente no que se refere ao tratamento dado aos objetos dessa disciplina, os quais passaram a ser abordados na perspectiva da interação, isto é, no uso da língua em diversas práticas sociais nas quais estão implicados um eu que enuncia e um $t u$ que participa do processo enunciativo.

Todos esses estudos promoveram significativas mudanças nos documentos oficiais que orientam o ensino dessa disciplina, uma vez que se passou da visão prescritiva e normativa para a funcional. As proposições apresentadas nos PCN (1997), por exemplo, sinalizam que a língua não deve ser entendida como um sistema estático e fechado, mas como um meio que permite ao homem construir significados para o mundo e para a realidade que o cerca. Já a linguagem é "uma forma de ação interindividual orientada por uma finalidade específica (...)" (BRASIL, 1997, p. 22), que se realiza nas diversas práticas sociais. Embora não se faça menção à fonte, percebe-se que essa perspectiva revela traços dos postulados de Benveniste na medida em que apresenta a definição de língua a partir da interação social estabelecida com o outro, bem como à linguagem como elemento a partir do qual o indivíduo se constitui.

Em decorrência disso, as metodologias de ensino, que eram voltadas para a memorização de regras, passaram a se pautar pela criação de práticas concretas de produção textual, o que gerou a demanda pelo trabalho com os gêneros textuais, pela definição de contextos comunicativos específicos, a fim de que os alunos pudessem desenvolver habilidades linguísticas que lhes permitissem assumir-se como atores sociais e usarem a língua para se comunicar.

Nesse sentido, a categoria gênero textual assume um papel importante tanto no ensino da leitura quanto no da produção textual nas práticas escolares, uma vez que contempla seus usos e funções nas mais diversas situações comunicativas. Trabalhar a partir desse princípio implica "favorecer o desenvolvimento da competência comunicativa dos alunos e, para isso, os textos escritos e orais [devem ser] objetos de estudo (leitura, análise e produção)" (BEZERRA, 2010, p. 44). 
Os pressupostos desse tipo de trabalho trouxeram, então, impactos sobre o mercado editorial, que se empenha para atender às exigências dos $\mathrm{PCN}$ e também dos avaliadores dos livros didáticos. Veem-se, assim, manuais com diversos gêneros textuais, seções que parecem valorizar a reflexão sobre o uso da língua em detrimento da prescrição de regras gramaticais e propostas de produção de texto que levam esse princípio em consideração. Percebe-se, porém, que nem sempre essa tentativa de adequação atinge as expectativas quando se trata das atividades relacionadas à produção de textos, uma vez que alguns elementos importantes implicados nesse processo parecem ser desconsiderados.

De acordo com Bezerra (2010), são chamados gêneros textuais "os textos particulares, que têm organização textual, funções sociais, locutor e interlocutor definidos" (BEZERRA, 2010 , p. 43). Nessa perspectiva, acredita-se que, ao propor a produção de um texto, as categorias gênero textual, situação de produção, propósito e participantes (locutor e alocutário), esboçadas por Bezerra, deveriam ser consideradas, pois, como se trata de uma abordagem que leva em consideração a língua em uso em práticas concretas, elas interferem nos modos de dizer, na maneira como o aluno irá tratar a temática proposta e se posicionar em relação a ela.

\section{Apresentação da situação-problema}

A coleção Produção de Texto para o Ensino Médio, produzida por Ana Paula Fonseca Vignoli, Isabel Adília Monteiro, Sandra Maria Fragoso Borges e Regina Lúcia Péret Dell'Isola, é composta por três volumes de livros didáticos (LD) que apresentam um trabalho específico com a escrita. Segundo salientam as autoras, os exemplares têm como objetivo fornecer aos estudantes recursos para que escrevam com autonomia e eficácia, exercendo a cidadania por meio de textos escritos.

Divididos em três seções (Praticando a palavra, Analisando a composição textual e Produzindo texto), esses LD buscam propor, no estudo dos gêneros e das tipologias textuais, uma reflexão sobre a enunciação. Além disso, contemplam os fatores linguísticos e extralinguísticos envolvidos nas situações comunicativas.

No livro do professor, especificamente, na seção "Apresentação da Coleção", nota-se a preocupação das autoras em evidenciar 
a que correntes teóricas se filiam para fundamentar o trabalho que propõem com a produção de texto no ensino médio. Nesse sentido, elas lançam mão das proposições de Bakhtin e Benveniste para mostrar que, em decorrência da mudança que houve na concepção de língua, adotam-na como um sistema de caráter interacionista, "sujeito à ação dos falantes que dela fazem uso em parceria". (VIGNOLI et al. 2014, p. 3). Citam ainda Koch (2002), Marcuschi (1999) e Geraldi (1996), com o intuito de elucidar a relação direta entre as concepções de língua, sujeito e texto, bem como o modo de ensinar língua. Ademais, prescrevem que compete ao professor de Produção de Texto "propor situações em que o aluno possa produzir textos nos quais se considere um leitor específico, a situação de produção em que se encontram os interlocutores e as intencionalidades dos produtores" (VIGNOLI et al. 2014, p. 4).

Fica evidente, nesse texto introdutório, que as autoras concebem a língua como atividade e, consequentemente, o texto como processo de interação entre sujeitos que, em determinadas situações comunicativas, têm intenções específicas. Delineada, assim, essa filiação teórica, parte-se do pressuposto de que as atividades apresentadas nessa coleção irão contemplar as categorias necessárias para que o processo de produção de texto seja vislumbrado pelo aluno como algo que se constitui na e pela interação.

A partir desse discurso frente às concepções teóricas, pretendo analisar a seção do livro didático, intitulada "Produzindo texto", a fim de verificar se as categorias listadas como prementes no processo de escrita são consideradas nas atividades propostas. Para isso, far-se-á, primeiramente, o levantamento de algumas concepções teórico-metodológicas apontadas pelas autoras como importantes para orientar o trabalho com o gênero textual no ensino de língua portuguesa, especificamente no que se refere às práticas da escrita, para, em seguida, analisar as atividades propostas nos $\mathrm{LD}$.

\section{Concepções teóricas subjacentes no discurso das autoras dos LD}

$\mathrm{Na}$ abertura de cada volume que compõe a coleção de livros didáticos Produção de Texto para o Ensino Médio, as autoras apresentam os pressupostos teóricos que fundamentam o trabalho realizado por elas. São evidenciadas, por exemplo, as concepções de língua, do processo enunciativo, bem como o 
modo segundo o qual se devem abordar os objetos de ensino da disciplina língua portuguesa.

Primeiramente, elas esclarecem que buscam romper com os paradigmas educacionais inadequados às exigências do mundo moderno para empreenderem um trabalho em que o alunoaprendiz seja sujeito ativo capaz de produzir textos cujos efeitos de sentido sejam percebidos. Além disso, salientam que, "desde Bakhtin (1992) e Benveniste (1991), a concepção de língua é redimensionada de uma estrutura estática para um sistema de caráter interacionista de linguagem, sujeito à ação dos falantes que dela fazem uso em parceria". (VIGNOLI et al. 2014, p. 3).

Nesse sentido, mostram a importância de se pensar a partir dessa ótica interacionista, já que, como toda palavra "é determinada tanto pelo fato de que procede de alguém, como pelo fato de que se dirige para alguém" (BENVENISTE apud VIGNOLI et al. 2014, p. 3), é preciso levar em consideração tanto as condições de produção do texto quanto o propósito em relação ao público a que ele se destina.

As autoras também salientam que cada concepção de língua e linguagem pressupõe uma concepção de texto e de sujeito. Assim, elas citam e parafraseiam Koch (2002) para esclarecer que se embasaram na concepção de língua como atividade e de texto como processo.

Fica esclarecido, também, que, de acordo com Geraldi (1996), a elaboração de textos é entendida por elas como uma atividade interindividual e, por isso, julgam ser imprescindível a especificação de fatores citados por Marcuschi (1999 apud VIGNOLI et al. 2014) como relevantes na produção de textos, "tais como participantes, objetivos, público, tema, conhecimento linguístico (linguístico e enciclopédico, do autor e do leitor), estilo, situação comunicativa e gênero do texto" (VIGNOLI et al. 2014, p. 4).

Essa é a declaração feita pelas autoras mais importante para este estudo, já que ela aponta para uma perspectiva de ensino sociointeracionista e concebe a produção de texto como uma atividade em que convergem as intencionalidades de um sujeito que enuncia e as expectativas de um outro que se vislumbra no processo enunciativo. Dessa forma, será tomada como referência no processo de análise das atividades presentes nos LD. 


\section{alemos \\ ESPUC \\ BELO HORIZONTE - N. $29-2016$}

\section{Análise dos dados}

Ao analisar o corpus deste trabalho, isto é, o discurso das autoras sobre as concepções teóricas axiais dos LD e as 26 propostas de produção de texto apresentadas especificamente na seção "Produzindo o texto" dos três volumes que compõem a coleção de livros didáticos em questão, buscou-se verificar se essas atividades, de fato, levam em consideração as categorias gênero textual, situação de produção e, principalmente, interlocutores e suas intencionalidades. Tal recorte foi feito porque, conforme apontado pelas autoras, esses elementos interferem no processo enunciativo e determinam como este será.

Tomemos, então, como primeira referência a proposta apresentada na página 17 do volume 1 .

FIGURA 1 - Propostas de produção de texto.

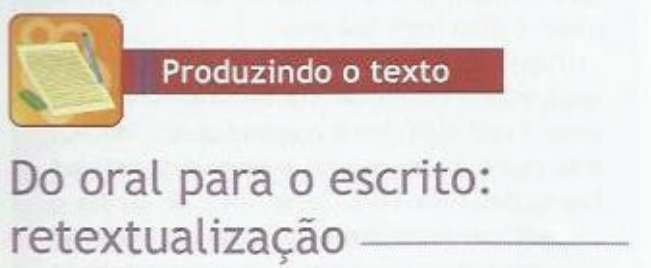

17. Ouça... e escreva...

Agora é a sua vez de exercer a autoria, com seu próprio estilo, criando um texto escrito, com base na audiçảo. Você vai ouvir uma notícia veiculada pela Internet e, usando recursos da língua escrita, vai contar a noticia que você ouviu.

Construa o seu próprio texto, individualmente, atendendo às orientaçōes já citadas nesta unidade.

Fonte: VIGNOLI et al., 2014, p. 17, v. 1.

Nota-se, logo no subtítulo da seção, um aspecto bastante apontado pelos Parâmetros Curriculares Nacionais (PCN), que é o trabalho com a oralidade. Além disso, mesmo que não tenha sido especificado, pode-se inferir que o gênero textual em questão é uma notícia, ao se levar em consideração o contexto apresentado. Nesse sentido, pode-se dizer que o exercício mostra-se coerente com as orientações expostas nesse documento oficial. Há, no entanto, uma lacuna no que se refere à definição do público-alvo, já que não se cria uma situação em que fique definido quem será o leitor do texto produzido pelo aluno. 
Dessa forma, ao se levar em consideração esta categoria, participantes (enunciador e enunciatário), constatou-se que 54\% das propostas de produção de texto analisadas não determinam um público específico. Conforme se observa na figura 2, algumas atividades apresentadas nesses LD desconsideram as ideias anunciadas nas bases teóricas mencionadas pelas autoras.

FIGURA 2 - Propostas de produção de texto.

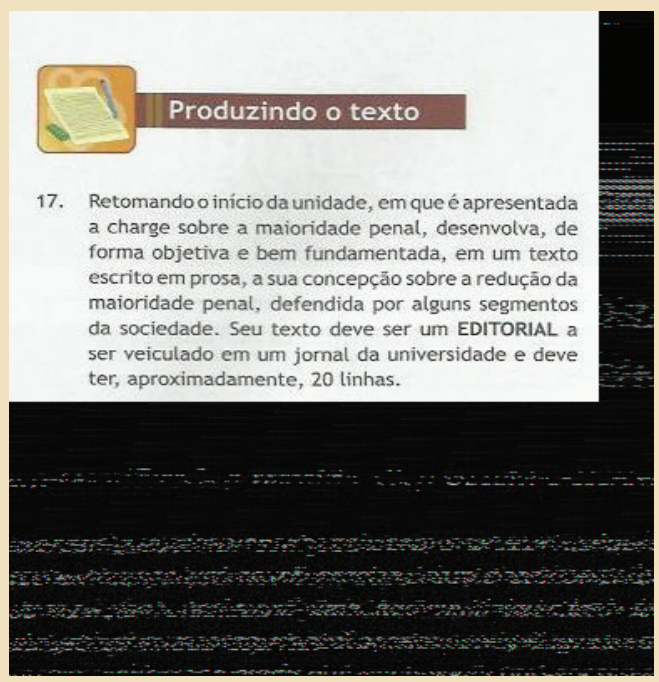

Fonte: VIGNOLI et al., 2014, p. 63, v. 3.

Diana Pessoa de Barros (2004), afirma que "(...) as imagens dos interlocutores ou os simulacros dos sujeitos constroem e determinam as relações de comunicação e de interação entre sujeitos" (BARROS, 2004, p. 45). Nesse sentido, acredita-se que a especificação dessa categoria se faz necessária, pois, como as próprias autoras dos LD asseveram, é a partir da projeção desse outro, dessa ação entre parceiros que se selecionam a modalidade linguística que será utilizada e os tipos de fatos ou procedimentos discursivos mais adequados para atingir o propósito do enunciador.

As propostas em questão, por exemplo, ao não especificarem quem o enunciador terá de convencer, se são adolescentes ou adultos, pertencentes ou não a grupos que são adeptos às ideologias em que ele acredita, cerceiam a possibilidade de o aluno lançar mão de argumentos mais apropriados para a defesa de sua tese. Consequentemente, tornam a produção de texto uma ação menos significativa para o aprendiz. Bezerra (2010) advoga contra essa perspectiva, pois, segundo ela, "é justamente a desconsideração de aspectos comunicativos e interacionais que contribui para que os alunos e professores se preocupem mais com a forma do texto do que com sua função" (BEZERRA, 2010, p. 44). 


\section{ademoses

Já no que se refere à especificação do gênero textual, percebeuse que $77 \%$ das propostas contemplam essa categoria, que é abordada, às vezes, de forma explícita, como se observa na figura 3, ou de modo que ela possa ser deduzida pelo contexto (figura 4).

FIGURA 3 - Propostas de produção de texto.

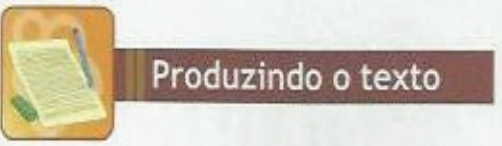

17. Retomando o início da unidade, em que é apresentada a charge sobre a maioridade penal, desenvolva, de forma objetiva e bem fundamentada, em um texto escrito em prosa, a sua concepção sobre a redução da maioridade penal, defendida por alguns segmentos da sociedade. Seu texto deve ser um EDITORIAL a ser veiculado em um jomal da universidade e deve ter, aproximadamente, 20 linhas.

Fonte: VIGNOLI et al., 2014, p. 43, v. 2.

FIGURA 4 - Propostas de produção de texto.

Produzindo o texto

\section{Descrição de personalidades -}

10. Em seguida, apresentam-se as descriçōes de quatros personalidades internacionalmente conhecidas. Você deve ler esses textos, comentá-los com os colegas e, depois, escolher uma outra personalidade para fazer uma descrição completa como as que você lerá agora.

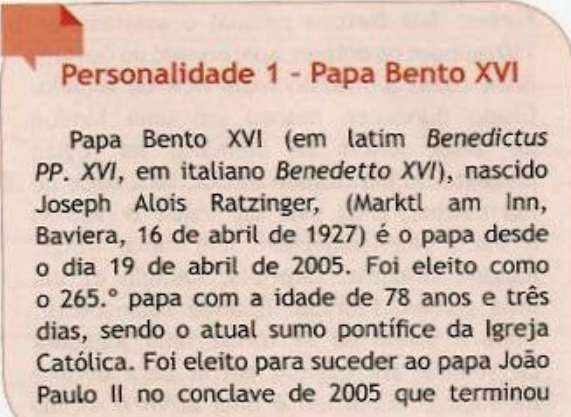

Fonte: VIGNOLI et al., 2014, p. 57, v. 1. 
O apontamento dessa categoria mostra não apenas um trabalho voltado para as situações reais de uso da língua, como também uma proposta que leva em consideração a necessidade de desenvolver no aluno a capacidade de saber mobilizar diferentes modos de dizer em função da situação comunicativa. Sendo assim, entende-se que o estudo do gênero é uma forma de fazer com que o processo de aprendizado seja mais significativo para o aluno, contribuindo para que ele desenvolva suas habilidades linguísticas na interação com o objeto de estudo.

Quanto à situação de produção, verificou-se que 50\% das atividades não levam essa categoria em consideração, uma vez que apresentam apenas, ora o gênero textual, ora o propósito e desconsideram os participantes e suas intencionalidades na situação comunicativa. A figura 5 confirma tal assertiva.

FIGURA 5 - Propostas de produção de texto.

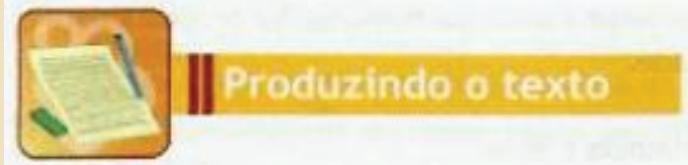

19. Reflita e crie uma analogia entre uma corrida de obstácı você. Expresse essa analogia em um parágrafo dissertatí

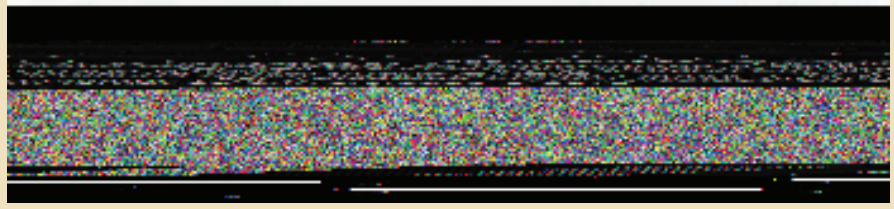

Fonte: VIGNOLI et al., 2014, p. 58, v. 2.

Pode-se depreender que, embora a proposta evidencie que o aluno deve produzir uma resenha, não menciona o local onde o texto será publicado ou os seus possíveis leitores. Acreditase que a omissão desse contexto comunicativo interfere no processo de tomada de decisão do aluno em relação à produção discursiva e desconsidera o caráter dialógico da linguagem, já que a construção do discurso de dá na relação com o outro.

Vale ressaltar ainda que se percebeu uma particularidade em relação ao volume 1 , já que, nele, as categorias em questão não foram contempladas como se esperava. Prova disso é que $75 \%$ das propostas não apresentavam uma situação de produção específica em que fossem explicitados um enunciador e suas incumbências em relação a um público determinado e tampouco apontavam qual gênero textual deveria ser produzido pelo aluno. Tais atividades abordavam apenas a tipologia trabalhada na unidade. Isso pode ser observado na figura 6 . 
FIGURA 6 - Propostas de produção de texto.

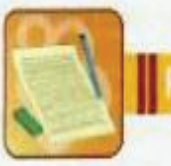

Produzindo o texto

19.

. Reflita e crie uma analogia entre uma corrida de obstáculos e o processo de formação intelec

Fonte: VIGNOLI et al., 2014, p. 72, v. 1.

Ao observar essa proposta, nota-se que ela leva em consideração apenas o tipo textual e desconsidera as categorias mencionadas pelas autoras. Isso compromete o caráter interativo da atividade, aproximando-a da tradicional redação, texto sem propósito comunicativo e que circula exclusivamente no contexto escolar.

\section{Considerações finais}

Percebe-se que há, hoje, por parte dos autores de LD um esmero em evidenciar que a produção de suas obras leva em consideração as prescrições estabelecidas pelos documentos oficiais sobre o ensino de língua. Observa-se também a tentativa de apresentar atividades que estejam fundamentadas em pressupostos teóricos consoantes com as diretrizes traçadas por esses parâmetros. Isso pode se dar pela aspiração a atender às exigências dos $\mathrm{PCN}$, as quais são avaliadas pela comissão que analisa os $\mathrm{LD}$. Muitas vezes, porém, isso não é transposto para as atividades que acabam se limitando a propostas descontextualizadas e que nada têm a ver com as situações reais de uso da língua escrita.

$\mathrm{Na}$ coleção em questão, percebeu-se que cada unidade dos LD é encabeçada por um gênero textual específico e que boa parte das atividades contempla essa categoria. A partir dessa constatação, pode-se inferir que já é consensual a percepção de que o ensino de língua deve se pautar pelos gêneros textuais.

Por outro lado, encontrou-se uma quantidade expressiva - cerca de 50\% das atividades - que não abrange elementos fundamentais à situação de produção de textos. Categorias como enunciatário, suporte e intencionalidades do enunciador são apontadas, no discurso das autoras, como fundamentais para o processo de produção textual, mas desprezadas em algumas propostas.

Dessa forma, compreende-se que as atividades dos LD em 
questão não estão em consonância com os fundamentos teóricos, apontados pelas autoras, referentes ao entendimento de que o discurso se constrói em situações que levam em consideração a relação estabelecida entre parceiros. É preciso, portanto, que essa perspectiva seja vislumbrada em todas as atividades, a fim de que, na sala de aula, o caráter interativo de língua não se limite à abordagem do gênero textual, mas abarque todas as categorias evidenciadas no discurso teórico de que se apropriaram as criadoras desses materiais didáticos. Se, por exemplo, o outro interfere nos modos de dizer do enunciador, e compete ao professor levar isso em consideração, conforme ressaltam as autoras, ele não deveria ser delineado na proposta de produção de texto?

Acredita-se que, embora tenha havido significativas mudanças em relação ao ensino de língua e ao desenvolvimento de atividades meramente metalinguísticas e descontextualizadas, ainda há um abismo muito grande entre o discurso e a forma como se desenvolve o trabalho com a produção de texto na prática. Pode-se dizer que inúmeros são os estudos e pesquisas que sinalizam a importância dessa transposição e que já há, por parte dos autores de LD, a compreensão de que isso se faz necessário. Resta saber o que ainda compromete esse processo.

\section{ABSTRACT}

Taking as an object of study the collection of textbooks Text Production for High School, this study aims to analyze the treatment given to the production of text in order to verify that the proposed activities are coherent with the theoretical assumptions presented as a guide for the work in LD. For this, was elected a set of categories which, as I intend to show, are involved in the theoretical basis chosen by the authors. Thus, it will be verified if the work with writing, proposed in these activities, takes really into account the fact that language is an interactional character system in which the enunciator constitutes the relationship established with the enunciatee through the word.

Keywords: Text production. Textual genre. Textbook. Interaction.

\section{REFERÊNCIAS}

BARROS, Diana Luz Pessoa de. A comunicação humana. In: FIORIN, José Luiz (Org.) Introdução à linguística. 3. ed. São Paulo: Contexto, 2004. 
BEZERRA, Maria Auxiliadora. Ensino de língua portuguesa e contextos teórico-metodológicos. In: DIONÍSIO, Ângela Paiva; MACHADO, Anna Rachel; BEZERRA, Maria Auxiliadora. Gêneros textuais e ensino. São Paulo: Parábola Editorial, 2010.

BRASIL, Ministério da Educação e do Desporto. Secretaria de Educação Fundamental. Parâmetros Curriculares Nacionais Língua Portuguesa. Brasília, 1997.

GERALDI, João Wanderley. Linguagem e ensino. Campinas: ALB; Mercado de Letras, 1996.

GERALDI, João Wanderley (Org.). O texto na sala de aula. 4. ed. São Paulo: Ática, 2006.

$\mathrm{KOCH}$, Ingedore Villaça. Desvendando os segredos do texto. São Paulo: Cortez, 2002.

MARCUSCHI, Luiz Antonio. Cognição, explicitude e autonomia no texto falado e escrito. Conferência pronunciada no III ELFE - Encontro de língua falada e ensino. Maceió: UFAL, 1999.

MEURER, José Luiz; BONINI, Adair; MOTTA-ROTH, Désirée. Gêneros: teorias, métodos, debates. São Paulo: Parábola, 2005.

ROJO, Roxane. Gêneros do discurso/texto como objeto de ensino de línguas: um retorno ao trivium? In: SIGNORINI, Inês (Org.). [Re]discutir texto, gênero e discurso. São Paulo: Parábola, 2008.

SANTOS, Carmi Ferraz. O ensino da leitura e a formação em serviço do professor. Revista Teias, Rio de Janeiro, v. 3, n. 5, jan./jun., p. 29-34, 2002.

VIGNOLI, Ana Paula Fonseca et al. Produção de texto para o ensino médio. Belo Horizonte: Educacional, 2014. v. 1.

VIGNOLI, Ana Paula Fonseca et al. Produção de texto para o ensino médio. Belo Horizonte: Educacional, 2014. v. 2.

VIGNOLI, Ana Paula Fonseca et al. Produção de texto para o ensino médio. Belo Horizonte: Educacional, 2014. v. 3.

Recebimento: 13/08/2016

Aceite: 18/09/2016 